\title{
STUDY OF FATAL POISONING IN A DISTRICT HOSPITAL OF WEST BENGAL
}

\author{
Arijit Datta ${ }^{1}$, Preeti Tiwari², Swapnodeep Sarkar ${ }^{3}$ \\ 1 Post Graduate, Department of Forensic Medicine, Yenepoya Medical College. \\ 2 Post Graduate, Department of Community Medicine, Yenepoya Medical College. \\ 3 Post Graduate, Department of Community Medicine, Medical College, Kolkata.
}

ABSTRACT
Poisoning is an emerging problem worldwide. According to WHO, 3 million acute poisoning cases with 2,20,000 deaths occur
annually. Of these, 90\% of fatal poisoning occurs in developing countries mainly among agricultural workers. It is estimated that
more than 50,000 people die every year from toxic exposure in India.

\section{OBJECTIVES}

1. To study the current trend of poisoning in a District of West Bengal.

2. To know the burden of pesticide poisoning in society.

\section{MATERIAL AND METHODS}

A hospital based retrospective cross sectional study was conducted in a district hospital of West Bengal. Ethical clearance was taken from Ethics Committee. All the registered cases of poisoning in a district hospital during the study period were included in the study. Data was collected from medico-legal register and respective case sheets using pre-structured and validated questionnaire containing demographic and medico-legal aspects of poisoning for the period of 2 years (March 2014-March 2016). Data was analysed using the SPSS version 16 software. Descriptive statistics were reported as mean (SD) for continuous variables and frequency (percentage) for categorical variables.

\section{RESULT}

Total 7280 patients reported to casualty department over two years; $5.21 \%$ were reported to be the poisoning cases. Out of total 380 poisoning cases, $84(22.10 \%)$ patients died. Maximum poisoning cases were from rural area falling mainly in the age group of 21-30 and above 50 years. Organ phosphorus poisoning was noted in $46.42 \%$ of reported cases.

\section{CONCLUSIONS}

Based on the study findings, we could understand the trend of poisoning in the study area. It is very important to identify these changing trends in the study area, as it will be helpful for policy makers to equip health care institutions which can lead to better management of cases and reduction in the mortality related to poisoning.

\section{KEYWORDS}

Poisoning, Organophosphorus, Forensic Toxicology.

HOW TO CITE THIS ARTICLE: Datta A, Tiwari P, Sarkar S. Study of fatal poisoning in a district hospital of west Bengal. J. Evolution Med. Dent. Sci. 2016;5(42):2571-2573, DOI: 10.14260/jemds/2016/601

\section{INTRODUCTION}

Acute poisoning is a medical emergency. Poisoning is an emerging problem worldwide. Poison can be defined as "a substance which can be solid, liquid or gas, which if introduced in a living body or brought in contact with any part will produce ill health or death by its constitutional or local effect or both." According to WHO, 3 million acute poisoning cases with 2,20,000 deaths occur annually. Of these, $90 \% .^{1}$ of fatal poisoning occurs in developing countries mainly among agricultural workers. It is estimated that more than $50,000 .^{2}$ people die every year from toxic exposure in India. Poisoning can be due to acute or chronic exposure of poison. Acute poisoning is more prevalent than the chronic poisoning.

Financial or Other, Competing Interest: None.

Submission 25-04-2016, Peer Review 06-05-2016,

Acceptance 09-05-2016, Published 24-05-2016.

Corresponding Author:

Dr. Arijit Datta

Post Graduate,

Department of Forensic Medicine,

Yenepoya Medical College,

Mangalore.

E-mail: arijitdatta18@gmail.com

DOI: $10.14260 /$ jemds $/ 2016 / 601$
Chronic poisoning refers to toxicity produced due to accumulation of the toxins in the body over the period of time as commonly seen in the case of continuous exposure to lead or other heavy metals.

There is poor maintenance and availability of data regarding poisoning at state level due to under-reporting of such cases. It has been estimated that about 5-6\% per lakh of population die due to poisoning every year. The commonest agents of poisoning in India appear to be pesticides, sedatives, chemicals, alcohol, plant toxins, household poison and snake bite, etc.

Poisoning can be occupational, accidental or intentional exposure. Accidental poisoning is mostly seen in paediatric case. It is one of the major causes of morbidity and mortality in children of developing countries.

Thousands of death is seen due to poisoning every year throughout the world. This study was carried out to assess various medico-legal poisoning cases in last two years. The results of this study will be helpful for policymakers to decide policies in order to reduce morbidity and mortality due to acute poisoning. Result of this study will be helpful to understand the medico-legal aspect of acute poisoning. 


\section{METHODS AND MATERIALS}

A hospital based retrospective cross sectional study was conducted in district hospital of West Bengal. Every district hospital is having a register book for maintaining the record of poisoning cases. The procedure and purpose of the study was informed and explained to the Medical Superintendent and permission was obtained from the Medical Superintendent to access the information from the record section, strictly for the purpose of this study. Data was collected from medico-legal register and respective case sheets using pre-structured and validated questionnaire containing demographic and medicolegal aspects of poisoning for the period of two years from March 2014 to March 2016 after taking ethical approval from Ethics Committee.

\section{Data was Collected on the Basis of:}

a) Gender distribution of poisoning cases.

b) Age group wise distribution of poisoning cases in both sexes.

c) Urban and rural distribution of poisoning cases.

d) Types of pesticide used.

All the registered cases of poisoning in a district hospital during the study period were included in the study and all undiagnosed cases were excluded from the study. Data was analysed using the SPSS version 16 software. Descriptive statistics were reported as mean (SD) for continuous variables and frequency (percentage) for categorical variables.

\section{RESULT}

Table 1 describes the total number of cases reported in casualty. Totally 7280 patients reported to casualty department over two years, that is from 2014-2016. Out of total $7280,380(5.21 \%)$ were poisoning cases.

Table 2 describe the number of mortality from total number of poisoning cases reported. Out of total 380 poisoning cases, $84(22.10 \%)$ patients died.

Figure 1 shows age distribution of study population. It shows that in year 2014-2015, maximum poisoning cases (34.02\%) were in the age group of 21-30 years, while in year 2015-2016 maximum poisoning cases (24.39\%) were reported in age group of above 50 years.

Table 3 shows gender distribution of cases. In year 20142015, majority of poisoning cases was seen among females (55.55\%). In year 2016-2017, male poisoning cases was more than female cases $(48.71 \%)$.

Table 4 shows Urban and Rural distribution of poisoning case. In our study, most of the poisoning cases were from rural area $(57.14 \%)$.

Table 5 describes the type of poisoning. In majority of cases, chemical analysis revealed organ phosphorus poisoning in both the years. Organ phosphorus type of poisoning was noted in $44.44 \%$ and $48.71 \%$ in $2014-2015$ and $2015-2016$ respectively.

\begin{tabular}{|c|c|c|c|}
\hline Year & $\begin{array}{c}\text { 2014-2015 } \\
\text { N (\%) }\end{array}$ & $\begin{array}{c}\text { 2015-2016 } \\
\text { N (\%) }\end{array}$ & Total \\
\hline $\begin{array}{c}\text { Total Cases } \\
\text { Reported in } \\
\text { Casualty }\end{array}$ & $\begin{array}{c}3700 \\
(50.82)\end{array}$ & $\begin{array}{c}3580 \\
(49.17)\end{array}$ & 7280 \\
\hline Poisoning Case & $\begin{array}{c}200 \\
(52.63)\end{array}$ & $\begin{array}{c}180 \\
(47.37)\end{array}$ & 380 \\
\hline $\begin{array}{c}\text { Mortality in } \\
\text { Poisoning Case }\end{array}$ & $\begin{array}{c}45 \\
(53.57)\end{array}$ & $\begin{array}{c}39 \\
(46.42)\end{array}$ & 84 \\
\hline \multicolumn{4}{|c|}{ Table 1: Number of Cases Reported in Casualty } \\
\hline
\end{tabular}

\begin{tabular}{|c|c|}
\hline Reported Cases & $\begin{array}{l}\text { Poisoning } \\
\text { N (\%) }\end{array}$ \\
\hline $\begin{array}{l}\text { Total Cases Reported in Casualty (N=7280) } \\
\text { (March } 2014 \text { to March 2016) }\end{array}$ & $380(5.21)$ \\
\hline Mortality $(\mathrm{N}=380)$ & $84(22.10)$ \\
\hline \multicolumn{2}{|l|}{ Table 2: Mortality in Casualty Cases } \\
\hline
\end{tabular}

\begin{tabular}{|c|c|c|c|}
\hline Sex & $\begin{array}{c}\text { 2014-2015 } \\
\text { N (\%) }\end{array}$ & $\begin{array}{c}\text { 2015-2016 } \\
\text { N (\%) }\end{array}$ & $\begin{array}{c}\text { TOTAL } \\
\text { N (\%) }\end{array}$ \\
\hline Male & $20(44.45)$ & $19(48.71)$ & $39(100)$ \\
\hline Female & $25(55.55)$ & $20(51.29)$ & $45(100)$ \\
\hline Total & 45 (53.57) & 39 (46.43) & $\mathbf{8 4}(\mathbf{1 0 0})$ \\
\hline \multicolumn{4}{|c|}{ Table 3: Gender Distribution } \\
\hline
\end{tabular}

\begin{tabular}{|c|c|c|c|}
\hline Locality & $\begin{array}{c}\mathbf{2 0 1 4 - 2 0 1 5} \\
\text { N (\%) }\end{array}$ & $\begin{array}{c}\mathbf{2 0 1 5 - 2 0 1 6} \\
\text { N (\%) }\end{array}$ & $\begin{array}{c}\text { TOTAL } \\
\text { N (\%) }\end{array}$ \\
\hline Urban & $19(52.77)$ & $17(47.22)$ & $36(42.85)$ \\
\hline Rural & $26(54.16)$ & $22(45.83)$ & $48(57.14)$ \\
\hline Total & $\mathbf{4 5}(53.57)$ & $\mathbf{3 9}(46.42)$ & $\mathbf{8 4}(100)$ \\
\hline Table 4: Urban and Rural Distribution of Poisoning Case \\
\hline
\end{tabular}

\begin{tabular}{|c|c|c|c|}
\hline $\begin{array}{c}\text { Type of } \\
\text { Poisoning }\end{array}$ & $\begin{array}{c}\mathbf{2 0 1 4 -} \\
\mathbf{2 0 1 5} \\
\mathbf{N ~ ( \% )}\end{array}$ & $\begin{array}{c}\mathbf{2 0 1 5 -} \\
\mathbf{2 0 1 6} \\
\mathbf{N ~ ( \% )}\end{array}$ & $\begin{array}{c}\text { Total } \\
\text { N (\%) }\end{array}$ \\
\hline $\begin{array}{c}\text { Organophosphorus } \\
\text { Poisoning }\end{array}$ & $\begin{array}{c}20 \\
(44.44)\end{array}$ & $\begin{array}{c}19 \\
(48.71)\end{array}$ & $\begin{array}{c}39 \\
(46.42)\end{array}$ \\
\hline Non-Conclusive & $0(0)$ & $0(0)$ & $0(0)$ \\
\hline Drugs & $0(0)$ & $0(0)$ & $0(0)$ \\
\hline Corrosive & $8(17.77)$ & $6(15.38)$ & $14(16.66)$ \\
\hline Insecticide & $9(20)$ & $8(20.51)$ & $17(20.23)$ \\
\hline Animal bite & $0(0)$ & $0(0)$ & $0(0)$ \\
\hline Alcoholic & $8(17.77)$ & $6(15.38)$ & $14(16.66)$ \\
\hline Total & 45 (53.57) & $\mathbf{3 9}(\mathbf{4 6 . 4 2 )}$ & $\mathbf{8 4}(\mathbf{1 0 0})$ \\
\hline \multicolumn{4}{|c|}{ Table 5: Types of Poisoning } \\
\hline \multicolumn{4}{|c}{}
\end{tabular}

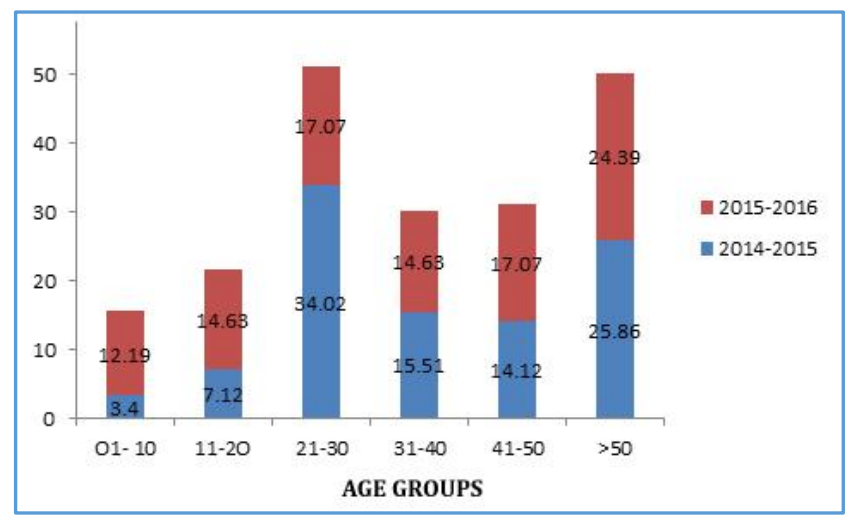

Fig. 1: Age Distribution

\section{DISCUSSION}

In the present study, mean age of poisoning was found to be $28.58 \pm 15.04$ and $28.56 \pm 15.21$ in 2014-2015 and 2015-2016 respectively.

In our study, there were 7280 cases reported in casualty over the period of two years and 380 were the confirm poisoning cases, which constituted $5.21 \%$ of total reported cases in casualty over two years. Mortality among the reported cases was $22.10 \%$.

The frequency of occurrence of poisoning in our study was found to be higher in age group of 21-30 years in 2014-2015 
(34.02\%), while in 2015-2016 majority (24.39\%) of cases were from above 50 years. Chavan KD et al, ${ }^{3}$ Chaudhary BL et $\mathrm{al}^{4}{ }^{4}$ found $50.63 \%$ and $29.5 \%$ of poisoning cases among $21-30$ years. This may be due to stress and challenges in day-to-day life pertaining to domestic, economic and marital problems.

In our study more number of poisoning cases was reported among females in year 2014-2015 (55.55\%), which coincide with the findings of Aggarwal P et al, ${ }^{5}$ Kristinsson J et al ${ }^{6}$ and Hovda KE et al. ${ }^{7}$

While in year 2015-2016 there was higher poisoning cases among males (48.71\%), which was similar to the findings of the studies conducted by Chaudhary BL et al,4 Tandon SK et al, ${ }^{8}$ Singha US et al, ${ }^{9}$ Dash SK et al, ${ }^{10}$ Kanchan T et al ${ }^{11}$ and Singh et $\mathrm{al}^{12}$ showed higher poisoning cases among males.

In our study, $57.14 \%$ of cases were from rural area and $42.85 \%$ of cases from urban area. This finding is different from Raj KS et al,13 who reported $72.11 \%$ cases from urban area.

In present study, majority of poisoning cases were due to organophosphorus poison (46.42\%) followed by insecticides (20.23\%).

Our findings were same as stated by Gannur et al, 14 in his study. He reported $45.62 \%$ of organophosphorus poisoning. Vivekanandan et al $^{15}$ reported organophosphorus poisoning in $31 \%$ of cases and insecticide poisoning in $16.2 \%$.

In our study corrosive poisoning and alcohol poisoning was noted in $16.66 \%$ of cases, while in study conducted by Job $\mathrm{C}^{16}$ corrosive poisoning was found only in $5.59 \%$ of reported cases.

No cases of drug poisoning or animal bite were observed in our study, which was similar to study conducted by Vivekanandan et al. ${ }^{13}$

\section{REFERENCES}

1. Reddy KSN. The essentials of forensic medicine and toxicology. India: Suguna Devi K. Internet Journal of Forensic Medicine and Toxicology 2012;29th edn:467.

2. Pillay VV. Textbook of Forensic medicine and toxicology. New Delhi: Jaypee brothers medical publisher; 2013; $4^{\text {th }}$ edn.

3. Chavan KD, Kachare RV, Goli SK. A retrospective study of acute poisoning in adult-in rural region of bleed district of Maharashtra. JMLAM 2002;14(1-2):7-9.
4. Chaudhary BL, Singh D, Tirpude BH. Trends of poisoining in the kasturba hospital, MGIMS, sevagram. Int J Med Toxicol Legal Med 2005;7(2):13-7.

5. Aggarwal P, Handa R, Wig N, et al. Cholinesterase inhibitor poisoning in adults-experience at AIIMS. JFMT 1995;12(3-4):30-2.

6. Kristinsson J, Palsson R, Gudjonsdottir GA, et al. Acute poisoning in Iceland: a prospective nationwide study. Clin Toxicol 2008:46(2):126-32.

7. Hovda KE, Bjornass MA, Skog K, et al. Acute poisoning treated in hospital in Oslo: a one year prospective study (I): pattern of poisoning. Clin Toxicol 2008;46(1):35-41.

8. Tandon SK, Qureshi GU, Pandey DN, et al. A profile of poisoning cases admitted in S.N medical college and hospital, Agra. JFMT 1996;13(1-2):10-2.

9. Singha US, Kapoor AK, Agnihotri AK, et al. A profile of poisoning cases admitted in SRN hospital, Allahabad with special reference to aluminium phosphide poisoning. JFMT 1999;16(1):40-3.

10. Dash SK, Raju AS, Mohanty MK, et al. Sociodemographic profile of poisoning cases. J Ind Acad Forensic Med 2005;27(3):133-8.

11. Kanchan T, Menezes RG. Suicidal poisoning in Southern India: gender differences. J Forensic Leg Med 2008;15(1):7-14.

12. Singh TB, Singh YL, Devi MR, et al. Poisoning cases in Manipur-a hospital based study. Indian Medical Gazette 2008;428-35.

13. Raj KS, Fazal MO, Bilal A. Organophosphorus compound poisoning; epidemiology and management (atropinisation Vs pralidoxime): a descriptive analysis in allied hospital Faisalabad. professional Med J 2008;15(4):518-23.

14. Gannur DG, Makka P, Reddy KSN. Organ phosphorus compound poisoning in Gulbarga region-a five year study. Indian Journal of Forensic Medicine and Toxicology 2008;2(1):3-11.

15. Vivekanandan K, Bhavya E, Punitha K. A study on poison cases and their management along with poison awareness educational strategies. Asian J Pharm Clien Res 2012;5(2):71-3.

16. Job C. A retrospective study of poisoning cases in Thrissur district of Kerala for the year 1995. JSIT 2009;5(1):23-7. 